\title{
Modeling and simulation of firing the boiler igniters of a gas-fired thermoelectric
}

\author{
Danilo P. e Silva ${ }^{1 *}$, Gabriel F. Fraga ${ }^{2 *}$, \\ José Leandro F. Salles ${ }^{1 *}$, Jussara F. Fardin ${ }^{2 *}$ \\ ${ }^{1}$ Postgraduate Program in Electrical Engineering, UFES, Vitória, ES, Brazil \\ ${ }^{2}$ Computation Engineering Departament, UFES, Vitória, ES, Brazil \\ danilo.p.silva@aluno.ufes.br \\ Valter Barbosa De Oliveira Junior \\ Arcelor Mittal Tubarão, Serra (ES), Brazil \\ valter.oliveira@nonachi.com
}

\begin{abstract}
This article presents the modeling and simulation of the sequence of operations of the boiler burner igniters in a gas-fired thermoelectric. The firing of the igniter is one of the steps necessary for the firing of the boiler burners. A kind of hybrid systems called Mixed Logical Dynamics Modeling scheme is proposed to model systems that have linear dynamic equations subject to linear inequalities involving real and integer variables. A simulation are reported and shows the steps and constraints to be met for starts the firing of the igniter.
\end{abstract}

\section{Introduction}

Dynamical systems represented by differential or difference equations, and by discrete events by means of logical rules, are called hybrid systems. There are several subclasses of hybrid systems for which techniques of analysis and/or simulations have been developed [1]. One of these subclasses is the structure called Discrete Hybrid Automata, DHA. The DHA results of the connection of discrete states of hybrid systems, provided by a Finite State Machine (FSM), with the continuous states of the system generated by a Piecewise Affine System (PWA) (see Fig- ure 11). Two connection elements make the interaction between both of them: the event generator and mode selector. The event generator is an object that generates events that meet a pre-established condition. These events and other external entrances trigger the state commutation of the finite states machine. The mode selector combines all these logical variables (states, entrances and events) to select the mode of continuous dynamics of the PWA. 


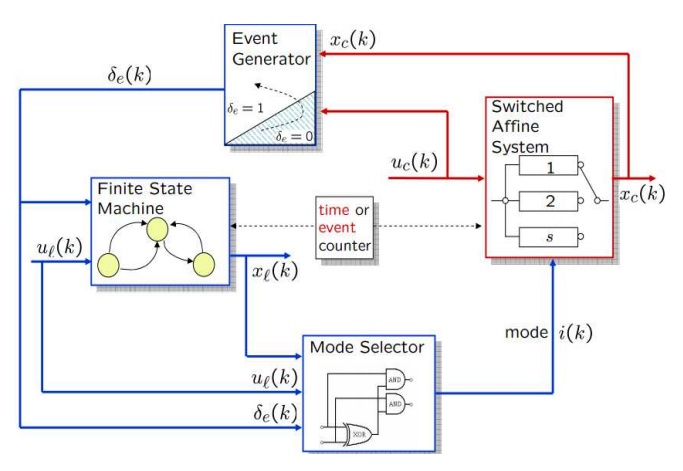

Figure 1: Discrete Hybrid Automata.

Another way to model hybrid systems is through Mixed Logical Dynamics Modeling (MLD), where time continuous dynamics, discrete event dynamics and constraints of a complex system are transformed into an integrated model, with logical restrictions and dynamics translated to mixed integer inequalities, involving continuous variables (real) and binary variables (or logical). MLD generalizes a wide set of models, including hybrid linear systems, finite elements state machines, some classes of discrete event systems, constraints linear systems, and non linear systems whose nonlinearities can be expressed (or approximated) through linear by part functions [2].

MLD systems can be found in several applications in the area of power systems, for example, in microgrid operations [3] and in the control of power generation in a gas thermoelectric.

This article aims to present modelling and simulation of a sequence of logical operations of firing the boiler igniter of a gas thermoelectric through a MLD system. Section 2 details the logical diagram of firing the igniter through a state machine. Section 3 show how to represent the hybrid system through the structure of the MLD model and presents simulation results. The conclusion is done in section 4.

\section{Firing the Boiler Burn- ers}

Consider the simplified process diagram of the fuel gas flow to the aquatubular boiler (hypothetical) showed in Figure 2 . having just two coke oven gas burners. The gas flow is controlled by the instrument FIC-10, actuating in a control valve $\mathrm{FV}-10$ whose opening varies continuously in time, performing regulatory control. On the other hand, there are on-off valves, also called shut-off valves, which can have only two positions (completely opened or completely closed), and are responsible for releasing or cutting off the gas flow to the burners. In this example, it is the valves FV-11A, FV11B, FV-11C e FV-11D. The permission to open or close these valves is determined though logical rules programmed in the sequence control system, which receives discrete signals as entrance (such as plant operation commands, pressure switches signals, flame sensors, etc.) and generates discrete output signals for actuation (opening or closing) of the locking valves. This arrangement results in dependency between the maximum admissible fuel flow and the number of ignited burners in the boiler, also resulting in changes in the dynamical behavior of the process, once depending on the number of ignited burners the gas mass moving through the pipes will be affected and the flow rate control valve (FV-10) shall work in different opening percentage ranges.

The sequence control will be ruled by interlocks that can be represented by logical diagrams, steps diagrams flowcharts. To fire the burner of a gas boiler, the following steps shall be performed by the system of management of the burners: Confirm that the furnace has been purged; 


\section{Blucher Proceedings \\ VIII Encontro Científico de Física Aplicada Blucher}

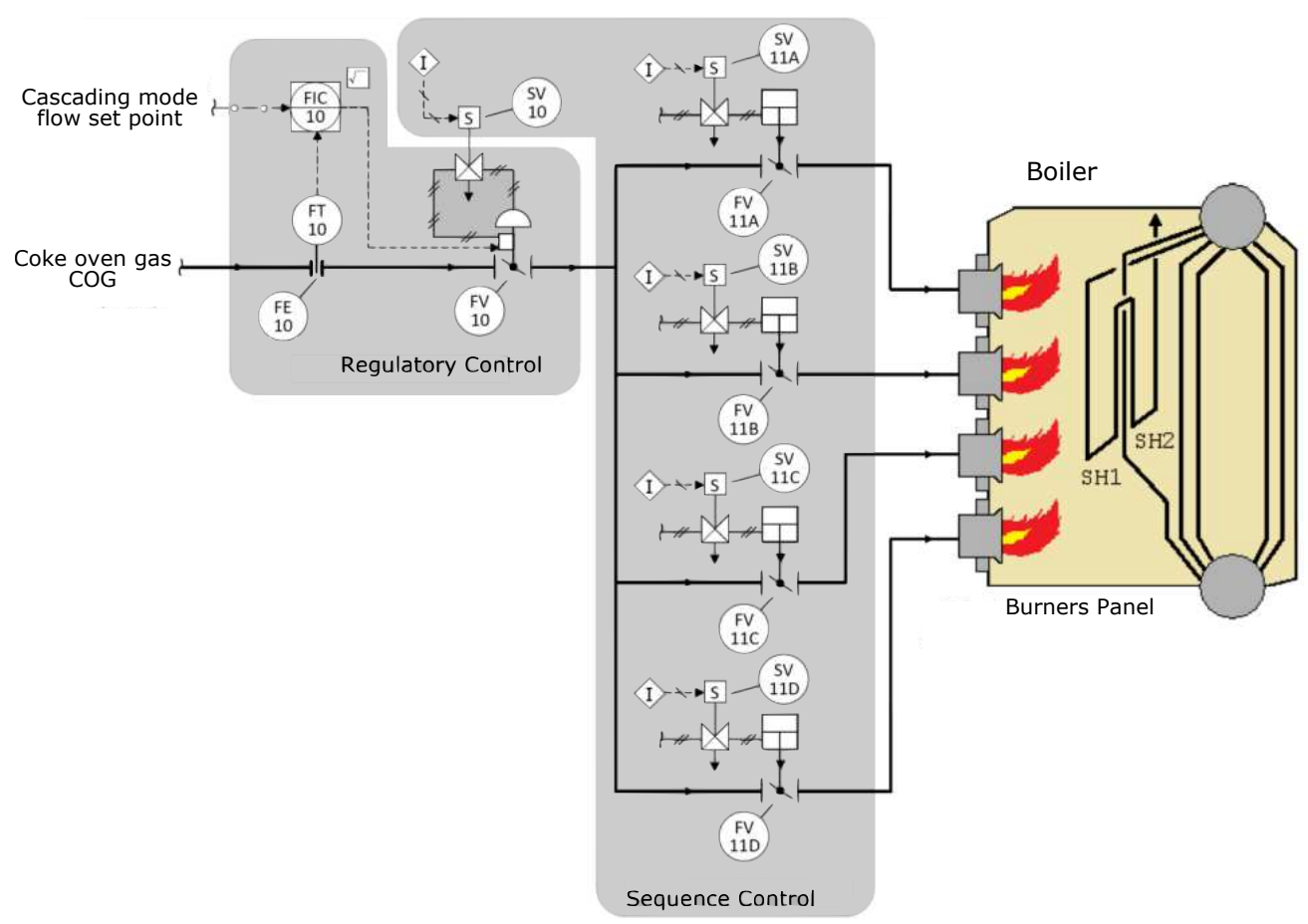

Figure 2: Simplified diagram of as aquatubular boiler.

Fire igniters; Fire flame stabilizers and Fire burners.

The logical diagram of firing the igniters through state machine is detailed later.

\subsection{State Machine of the Ig- niter}

One igniter can assume three discrete states: (1) off, (2) heading process, (on). The state change of the igniter depends on external entrances and on the logical conditions to be met, and the state machine of Figure 3 can represent this.

The operation of this state machine will happen as function of the entrance variables $u_{l}=\left[\begin{array}{llll}u_{l 1} & u_{l 2} & u_{l 3} & u_{l 4}\end{array}\right]$, of the discrete states of the machine state $\left(x_{l}=\right.$ $\left.\left[\begin{array}{lll}x_{l 1} & x_{l 2} & x_{l 3}\end{array}\right]\right)$, of the continuous state $\left(x_{c}\right)$ and of the auxiliary discrete variables $\left(d_{1}\right.$ e $d_{2}$ ), where: $u_{l 1}$ is equal to 1 if there is an igniter start command, and 0 otherwise; $u_{l 2}$ is equal to 1 if there is an igniter start permission, and 0 otherwise; $u_{l 3}$ is equal to 1 if there is an igniter stop command, and 0 otherwise; $u_{l 4}$ is equal to 1 if there is detection of burning flame on the igniter, and 0 otherwise; $x_{l 1}$ is equal to 1 and indicates the igniter state is off, which is equal to 0 otherwise; $x_{l 2}$ is equal to 1 and indicates the igniter state is firing, which is equal to 0 otherwise; $x_{l 3}$ is equal to 1 and indicates the igniter state is on, which is equal to 0 otherwise; $x_{c}$ is a continuous variable that indicates the present state of the time elapsed in the stabilization of the flame igniter; $d_{1}$ is equal to 1 in case the necessary time for stabilization of the igniter flame has been elapsed, otherwise 0 . $d_{2}=\left(x_{l 2} \wedge d_{1} \wedge \sim u_{l 4}\right) \vee\left(x_{l 3} \wedge \sim\right.$ $\left.u_{l 4}\right) \vee u_{l 3}$, when equal to 1 indicates a igniter stopping condition (need to turn off the igniter), which is equal to 0 otherwise. 


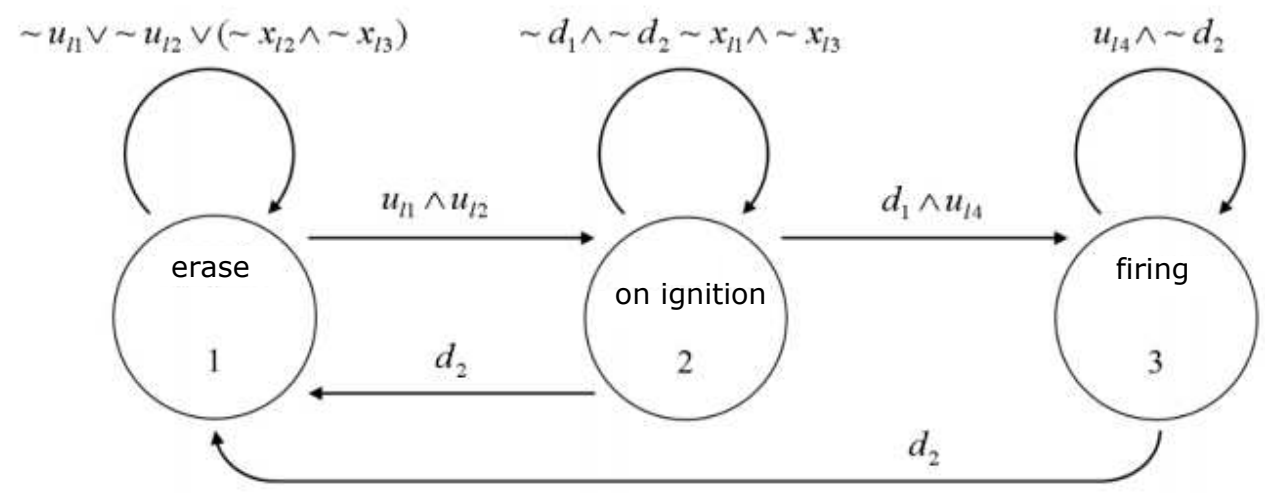

Figure 3: State Machine of the Igniter.

\section{Modeling and Simula- tion of a MLD Model}

The relevance and the generality of the MLD structure grounded by the capacity of including constraints to the system, priorization of constraints and heuristic knowledge. The general form of the MLD is defined by the following expressions:

$x(t+1)=A x(t)+B_{1} u(t)+B_{2} \delta(t)+B_{3} z(t)$

$y(t)=C x(t)+D_{1} u(t)+D_{2} \delta(t)+D_{3} z(t)$

$$
E_{2} \delta(t)+E_{3} z(t) \leq E_{1} u(t)+E_{4} x(t)+E_{5}
$$

Where $x \in R^{n_{c}} \times\{0,1\}^{n_{l}}$ are real and binary states, $\mathbf{u} \in R^{m_{c}} \times\{0,1\}^{m_{l}}$ are real and binary inputs, $y \in R^{p_{c}} \times\{0,1\}^{p_{l}}$ are binary and real outputs, $\delta \in\{0,1\}^{r_{l}}$ and $z \in R^{r_{c}}$ represent, respectively, auxiliary binary and real variables that define the operation modeso. The inequalities (1)(2) allow the representation of DHA. The transformation of state machine and dynamical equations of the hybrid systems to form MLD require the application of a set of rules, as shown in [5]. This task is generally long and exhaustive and, because of that, a computational tool was created to help generate the MLD model, which is called HYSDEL (HY- brid System DEscription Language) [6]. TIt is a compiler that produces matrices $A, B_{i}, C, D_{i} e E_{i}$ of Equations 1, 2 and 3, which are adequate for optimization, control and simulation of dynamical systems [6].

In figure 4 it is possible to observe the simulation results of the ignitor state machine through Hysdel. The inputs applied are indicated in the graphics to the left (a, $\mathrm{c}, \mathrm{e}, \mathrm{g}$ ) and the outputs generated by the module in the graphics to the right $(b, d, f$, h). Initially, the three discrete states (off, starting and on) are zeroed, so the state machine of the igniter determines that the present state of the igniter is off, making $x_{2}=1$. E. Then, at instant $1 \mathrm{~s}$, a start command is applied to the igniter $\left(u_{1}\right)$, but initially there is no start permission. Because of that, the continuous state of the timer $\left(x_{1}\right)$ is not changed. The start permission only occurs at instant $3 \mathrm{~s}$, making the igniter to reach the state starting, beginning the increment in the value of the timer to fire and stabilize the flame of the igniter. As the flame detection signal $\left(u_{4}\right)$ did not hold $1 \mathrm{~s}$ after the timer reached the value of $10 \mathrm{~s}$, the starting of the igniter was aborted, returning the igniter to the state off from the instant $15 \mathrm{~s}$ on. A new igniter start command is given at the instant 20 s and this time the flame detec- 

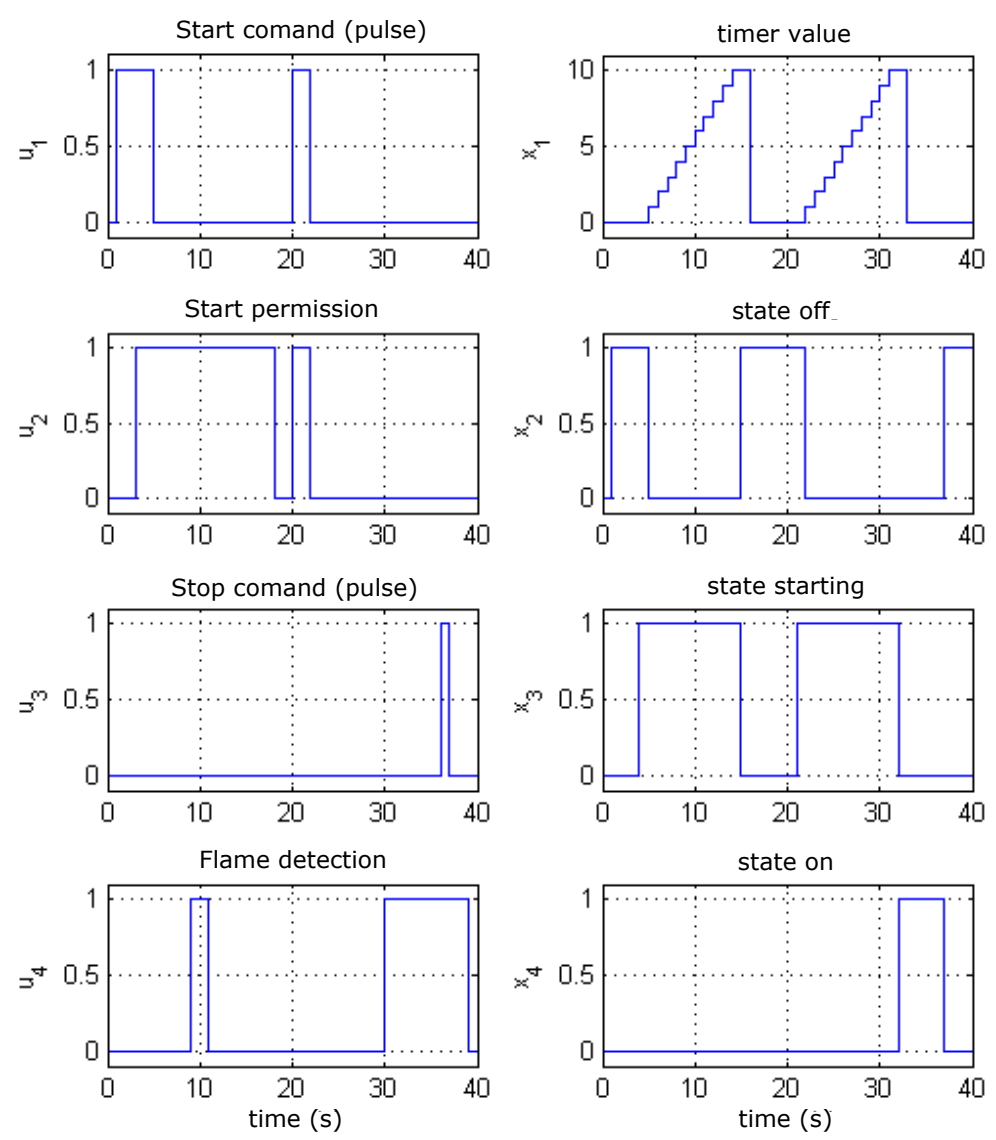

Figure 4: Modeling and Simulation of the burner's Igniter.

tion signal $\left(u_{4}\right)$ holds $1 \mathrm{~s}$ after $x_{1}$ reaches the value of $10 \mathrm{~s}$, so the igniter goes to the state on $\left(x_{4}=1\right)$. At last, at instant $36 \mathrm{~s}$ a stop command is applied to the igniter $\left(u_{3}=1\right)$, leading the igniter to the state off. It is important to observe that even though in this last state change that the system has been taken to the state off, which in fact implies closing the supply valve of the fuel gas of the igniter, the confirmation of flame detection (keeping $u_{4}$ at 1 ), does not change the state of the system, which in turn is ruled by a logic sequence.

\section{Conclusions}

Similar modeling and simulation to the one developed in this article can be performed to the firing of the stabilizers and burners of the boiler of a thermoelectric in order to perform flow rate control of the gas to be burned in the boilers. These hybrid models allow evaluating different operational situations, such as the existence of failures during the period of firing. In addition, in case this information is not adequately compensated by the control system fast enough, delay in the delivery of energy requested to the thermoelectric plant may happen. As suggestion for future studies, it is intended to 
integrate the flow rate control system to the management of power co-generation of the microgrid proposed by [4].

\section{Acknowledgments}

The authors thank Arcelor Mittal for the technical information.

\section{References}

[1] GARCÍA, M. J. P. Uma contribuição ao controle de sistemas comutados. Tese de Doutorado, Programa de Pós Graduação em Eng. de Controle e Automação, Universidade Federal de Santa Catarina, Florianópolis, Outubro 2009

[2] HAMMI, Y.; ZANZOURI, N.; KSOURI, M.. Faut-tolerant model predictive control of hybrid systems. International Journal of Computer Applications, Foundation of Computer Science, New York, v.43, p. 0975-8887, 2012.
[3] PARISIO, A.; RIKOS, E.; GLIELMO, L.; A Model Predictive Control Approach to Microgrid Operation Optimization, IEEE Transactions On Control Systems Technology, v. 22, n. 5. September, 2014.

[4] ANTOINE, M. Modeling and control of co-generation power plants: A hybrid system approach, IEEE Trans. Control Syst. Technol., v. 12, n. 5, p. 694-705, 2004.

[5] BEMPORAD, A.; FERRARITRECATE, G.; MORARI, M. Observability and controllability of piecewise affine and hybrid systems. IEEE Transactions on Automatic Control, v. 45, n. 10, p. 1864-1876, 2000.

[6] BEMPORAD, A.; MIGNONE, D.; MORARI, M. A framework for control, fault detection, state estimation and verification of hybrid systems. Proceedings of the American Control Conference, v.1, p. 134-138, 1999. 